\title{
Gravity observations along the eastern margin of the Tibetan Plateau and an application to the Lushan $M_{\mathrm{S}} \mathbf{7 . 0}$ earthquake
}

\author{
Wei-feng Liang $\cdot$ Yun-feng Zhao $\cdot$ Yun-ma Xu • \\ Yi-qing Zhu $\cdot$ Shu-song Guo • Fang Liu • \\ Lian Liu
}

Received: 1 June 2013/Accepted: 29 September 2013/Published online: 25 December 2013

(C) The Seismological Society of China, Institute of Geophysics, China Earthquake Administration, and Springer-Verlag Berlin Heidelberg 2013

\begin{abstract}
This paper introduces relative and absolute gravity change observations in the eastern portion of the Tibetan Plateau. We analyze and discuss a change that occurred in 2010 in the gravity along the eastern margin of the plateau and the relationship between this change and the 2013 Lushan $M_{\mathrm{S}} 7.0$ earthquake. Our results show that: (1) before the Lushan $M_{\mathrm{S}} 7.0$ earthquake, gravity anomalies along the eastern margin of the Tibetan Plateau changed drastically. The Lushan earthquake occurred at the bend of the high gradient zone of gravity variation along the southern edge of the Longmenshan fault zone. (2) The 2013 Lushan earthquake occurred less than $100 \mathrm{~km}$ away from the epicenter of the 2008 Wenchuan earthquake. Lushan and Wenchuan are located at the center of a fourquadrant section with different gravity anomalies, which may suggest that restoration after the Wenchuan earthquake may have played a role in causing the Lushan earthquake. (3) A medium-term prediction based on changes in gravity anomalies was made before the Lushan $M_{\mathrm{S}} 7.0$ earthquake, in particular, a prediction of epicenter location.
\end{abstract}

Keywords The eastern margin of the Tibetan Plateau - Gravity observation - Gravity change · Lushan earthquake $\cdot$ Medium-term prediction

\section{Introduction}

The Tibetan Plateau is one of the most active tectonic regions in the world. The eastern edge of the Tibetan Plateau is

W. Liang $(\bowtie) \cdot$ Y. Zhao $\cdot$ Y. Xu · Y. Zhu $\cdot$ S. Guo · F. Liu · L. Liu

Second Monitoring Center, China Earthquake Administration, Xi' an 710054, China

e-mail: 1wfbox@163.com known to be the major interactive region of the Tibetan, North China, and South China blocks. The uplift of the Tibetan block expands northward and eastward, colliding with the rigid North and South China blocks, resulting in strong tectonic deformation and a series of active faults. This tectonic motion and deformation make the Tibetan Plateau and its surrounding area the most active region of crustal deformation and seismicity in China. In recent years, earthquakes have occurred frequently along the eastern margin of the Tibetan Plateau. As a result, many studies have focused on active faults and neotectonic movements, spatial and temporal variations of regional gravity fields, regional crustmantle structure, integrated geophysical prospecting, and how to adequately prepare for large earthquakes in municipal areas. The $2008 M_{\mathrm{S}} 8.0$ Wenchuan earthquake, for example, that occurred in the middle of the Longmenshan earthquake zone has been thoroughly studied by a number of research teams (Hubbard and Shaw 2009; Jiang et al. 2009; Lou et al. 2008; Teng et al. 2008; Zhang et al. 2008; Zhu et al. 2009a, b, 2010).

The study of gravity changes allows us to understand the mechanisms that trigger strong earthquakes and advances our understanding of concurrent deep-seeded structural processes. Temporal and dynamic variations in the gravity field can reflect information about tectonic activity such as movement of material deep in the earth's interior and density changes within the crust (Chen et al. 1979). Gravity-field changes over time are intrinsically linked to the formation and development of earthquakes (Zhu et al. 2009b). In recent years, by using same-site continuous gravity observations or periodically repeated mobile gravity observations, many studies have observed gravity precursor information caused by a change in the source of an earthquake (Li et al. 2011; Xu 2003; Zhu et al. 2012a, b). These techniques have become some of the most important ways to analyze and predict 
seismic activity in the study of the characteristic analysis of the temporal and spatial variations in the gravity field, as well as in the study of gravity field characteristics before and after an earthquake. In 1983, the China Seismological Bureau (now the China Earthquake Administration) introduced high-accuracy gravimeters (LaCoste-Romberg model G, LCR-G) for gravity monitoring. Since then, many valuable observations have been available for use in earthquake prediction. Variations in the gravitational field have been observed before and after many earthquakes, such as the 1996 Lijiang $M_{\mathrm{S}} 7.0$ earthquake, the $2001 M_{\mathrm{S}} 8.1$ Kunlun earthquake, the $2003 M_{\mathrm{S}} 6.8$ Jiashi earthquake, the 2008 $M_{\mathrm{S}} 7.3$ Yutian earthquake and the $2010 M_{\mathrm{S}} 7.1$ Yushu earthquake in the Qinghai Province. The magnitude and scope of the gravitational changes correlate well with seismic magnitudes and source depths. Before the Wenchuan earthquake occurred in May 2008, the mobile surface gravity measurements showed that the maximum amplitude difference of cumulative gravity variations from 1998 to 2008 in the Longmenshan region was approximately $100 \times$ $10^{-8} \mathrm{~m} \mathrm{~s}^{-2}$, indicating a significant change in the regional gravity field before the earthquake occurred (Zhu et al. 2009a, 2010).

\section{The eastern margin of the Tibetan Plateau: gravity observations and data processing}

The eastern margin of the Tibetan Plateau features multiple faults. There are more NW-trending faults than NE-trending faults consisting of three Longmenshan main faults (Fig. 1a). The three Longmenshan main faults (Fig. 1b) are: the back range fault $(F 1)$, the central fault $(F 2)$, and the front-range fault $(F 3)$, from west to east. On the west side of the Longmenshan Mountain along the MaoxianWenchuan-Wolong line, the back range fault is also known as the Wenchuan-Maoxian fault, largely along the Wenchuan alpine valleys extending to Maoxian. On the east side along Anxian-Dujiangyan-Tianxian, the front fault is also known as the Anxian-Guanxian fault. The central fault is located in the middle of Longmenshan Mountain along the Yingxiu-Beichuan-Qingchuan, also known as Yingxiu-Beichuan-Qingchuan fault. These three imbricate faults are 20-24 km deep, converging into a lowangle thrust faults, as the Tibetan Plateau thrust above the Sichuan Basin. On the surface, the dip angle is $60^{\circ}-85^{\circ}$ for the back range fault and $50^{\circ}-80^{\circ}$ for the central fault. The two faults are manifested as brittle deformation superposed on the early (about 130 mio. years) ductile deformation (mylonite, tectonic schist). The front-range fault developed in the Mesozoic (Triassic, Jurassic, Cretaceous) strata and rocks. The surface inclination is also steeper, mainly brittle.
Gravity observations along the eastern margin of the Tibetan Plateau began in the late 80s. Provincial seismic monitoring networks were established in provinces such as Gansu, Shaanxi, Ningxia, Sichuan, and Yunnan. In the Hexi Corridor and the Qilian Mountains, the Hexi mobile gravity observation network was established by China's Second-Monitoring Center. The main goal of this network is to obtain relative gravity observations using LCR-G gravimeters to study the relationship between gravity variations and seismic activity. However, the regional gravity network monitoring area is limited to the area immediately surrounding China's major earthquake zones, with a single regional network coverage area of less than $100,000 \mathrm{~km}^{2}\left(3^{\circ} \times 3^{\circ}\right)$. As a result, it is difficult to track a wide range of gravity changes and spatial migration processes and to identify seismic hazard zones and determine earthquake magnitudes.

In 1998, led by the China Earthquake Administration and supported by the State Bureau of Surveying and Mapping, the Surveying and Mapping Bureau of the General Staff, and the Ministry of Education, the Crustal Movement Observation Network of China (CMONOC) was first established for joint gravity measurements at all base stations. The whole country was covered for joint measurements at 23 base stations (absolute gravity measurement points), 56 standard stations (relative gravity measurement points), and more than 300 transition points, for a total of nearly 400 measuring points. Subsequently, gravity surveys were carried out a total of four times, once each year in the years of 2000, 2002, 2005, and 2008. In 2012, the CMONOC conducted the sixth gravity measurement along the eastern margin of the Tibetan Plateau. Although the observation network provides nation-wide coverage, the general distance between test points is still large (100-200 km), and the period of repeated observation is also long (2-3 years). Gravity observations, to a certain extent, reflect the national trend of the gravity field. However, due to the lack of spatial and temporal resolution, observations cannot provide accurate variations in the gravitational field caused by seismic activity.

In 2004, the China Digital Seismic Network Mobile Crustal Deformation System-Earthquake Gravity Network was established by the China Earthquake Administration. The establishment of an earthquake gravity network was based on the China Gravity Basic Network and the gravity base network under the CMONOC. The earthquake gravity network was designed to contain 407 basic gravity points with an average distance between points of $80-200 \mathrm{~km}$, with 28 rings and several branch lines. The total measured length of the network is $46,000 \mathrm{~km}$, covering Mainland China, Hainan, Zhoushan, Hong Kong, Macao, and other islands. Data from the network is limited, however, because the first gravity 

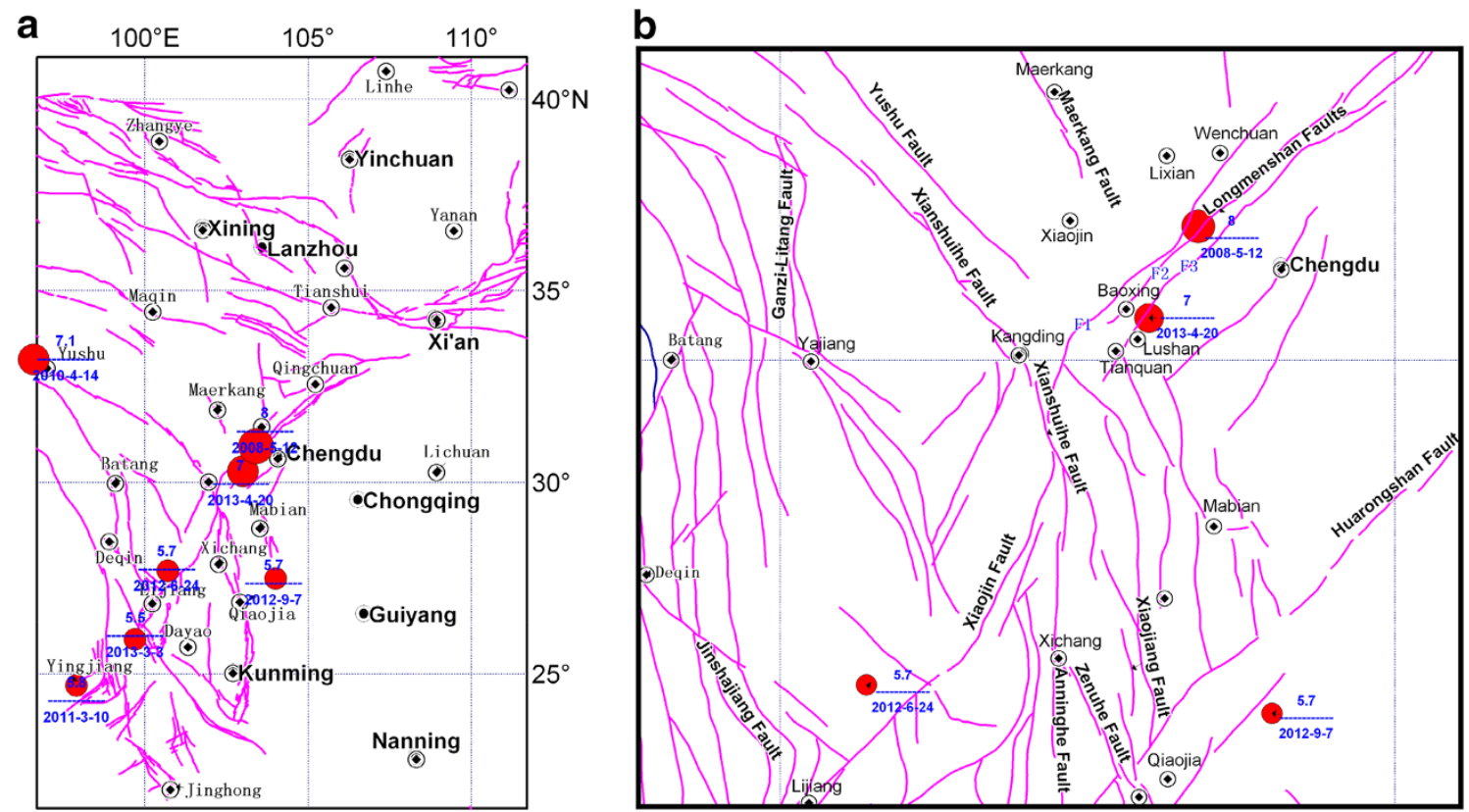

Fig. 1 The tectonics and earthquakes of the eastern Tibetan region

observations were only recorded in 2006 and 2007, including the eastern margin of the Tibetan Plateau.

In 2010, the China Earthquake Administration launched a special focus on seismic research: the gravity change refined monitoring network under the China integrated geophysical observations along the eastern margin of the Tibetan Plateau. The overall framework for this network is the national gravity base net. In the eastern margin of the plateau, the existing mobile seismic gravity monitoring networks have been reconstructed and optimized. In addition, six regional gravity networks including Yunnan, Sichuan, Gansu, Ningxia, Shaanxi have been connected to form a high-resolution monitoring network with a point-topoint spacing interval of $\sim 60-80 \mathrm{~km}$. There are a total of 10 absolute gravity points (Xi'an, Yinchuan, Lanzhou, Yushu, Chengdu, Xialatuo, Xichang, Xiaguan, Kunming, and Guiyang) and 400 relative gravity measurements. Both absolute and relative gravity observations were made a total of three times in 2010-2012 (Fig. 2). A relative gravity campaign was done with six gravimeters in each year in the same season, and each of the relative gravity campaigns was completed in 2 or 3 months. One FG5 absolute gravimeters were used for all of the absolute gravity measurements at a precision of $5 \times 10^{-8} \mathrm{~m} \mathrm{~s}^{-2}$. The high-precision relative gravity instruments (LCR-G, Burris, and CG-5) were used for all of the relative gravity measurements with a precision of $15 \times 10^{-8} \mathrm{~m} \mathrm{~s}^{-2}$.

Early data has been studied and reviewed in previous papers (Zhan et al. 2011; Zhu et al. 2009a, 2010). The goal of this paper is to analyze the high-precision gravity observations that have been recorded since 2010. The key

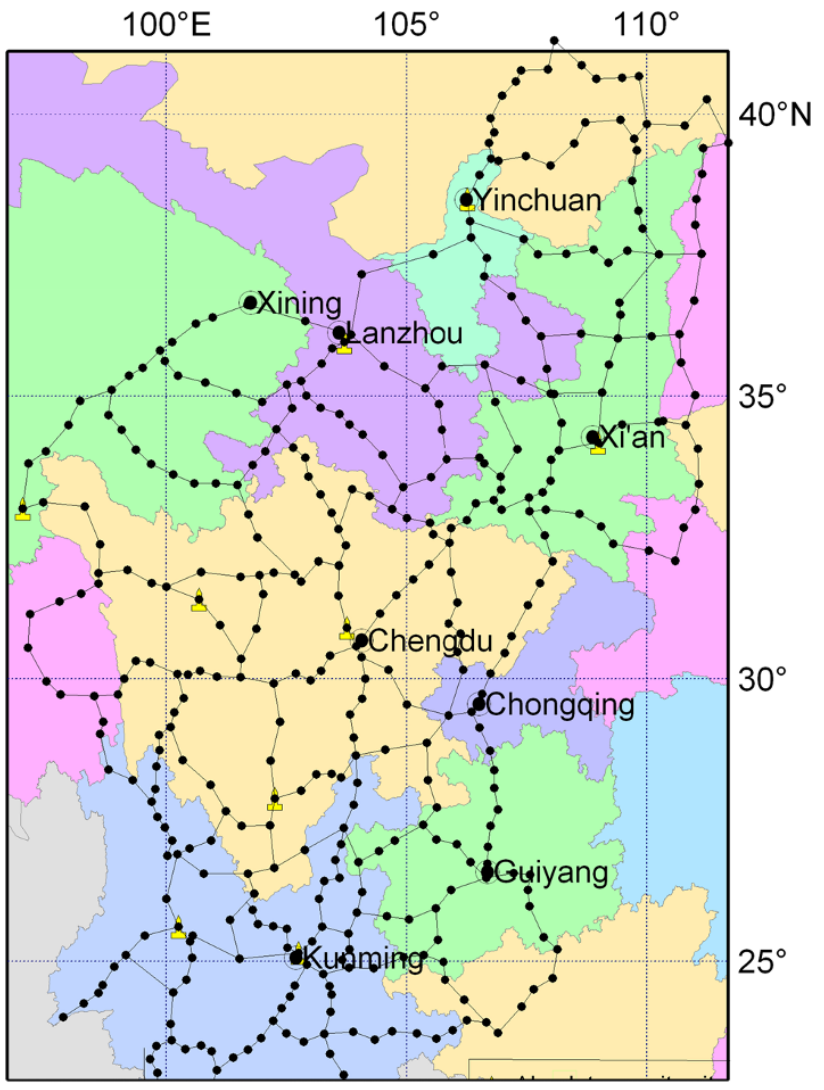

Fig. 2 A gravity monitoring network covering the eastern margin of the Qinghai-Tibet Plateau

step in data processing is to combine the absolute gravity observations from the eastern margin of the Tibetan Plateau with the mobile gravity observations. All of the absolute 
gravity points constitute a large-scale, relatively stable highprecision control network. The mobile gravity observations provide regular joint measurements and form a dynamic gravity-monitoring network on the eastern edge of the Tibetan Plateau. This data processing approach effectively guarantees the initial benchmark unity and stability for the entire eastern edge of the plateau. Gravity changes are calculated for each measuring point, resulting in accurate data on gravity field dynamics from this region of the plateau. First of all, a unified benchmark overall adjustment is done on the observation data of 2010-2012 of this gravitational optimization-monitoring network. In the latter part of data processing, a robust least square collocation algorithm was applied to the space domain filter the data and to further eliminate outliers and noise effects caused by surface interference. Because the average difference associated with estimation of hydrologic effects on gravity are well within the error budget of the gravity survey data (Zhu et al. 2010), and the schedule of conducting the ground gravity surveys in the same months in different years helps minimize seasonal hydrologic effects on the observed gravity changes at the same station between different years, so the effect of rain-fall should not be considered. On the other hand, data of vertical displacements in the eastern margin of the Tibetan Plateau are incomplete and sporadic, and the effect of the crust does not need to be accounted for. The ultimate goal of data processing is to obtain structure-related gravity changes. Different spatial and temporal scales pertaining to dynamic gravity changes can, therefore, be obtained and an analysis of the relationship between regional tectonics and seismic activity can be conducted in this region.

\section{Gravity field variations and the Lushan earthquake}

In this section, we show the dynamic changes in the gravity field extracted at multiple temporal scales from gravity data recorded since 2010. The changes in the gravity field on a 1-year time scale are shown to highlight differences in the dynamic evolution of the regional gravity field observed in different periods. The changes in the gravity field on a 2-year time scale are also shown to highlight cumulative gravity variations or the background characteristics of the gravity field over a longer period of prominent regional gravity field changes.

\subsection{1-Year gravity variations along the eastern margin} of the Tibetan Plateau

Figure 3a shows that during the period 2010-2011, dramatic changes in gravity occurred, alternating between positive and negative anomalies in the eastern margin of the plateau. Four areas of significant changes were observed. First, we identified a zone of dense gravity change, bounded by two lines (Batang-Xichang and Lixian-Mabian), featuring a four-quadrant distribution at the southern tip of the Longmenshan fault. The Wenchuan and Lushan earthquake zones are located in the center of this four-quadrant distribution. Second, after the 2010 Yushu earthquake, strips of negative gravity anomalies appear along the Sichuan-Yunnan block, which act directly on the Zemuhe Xiaojiang fault. These result in significant negative gravity changes from the north (Maqin, Yushu) to the south (Qiaojia, Kunming; Zhu et al. 2012a, b). Third, rapid gravity changes have been observed in the Sichuan-Yunnan boarder area, forming multiple local gravity anomaly zones. We also discovered high gradient zones and positive and negative gravity changes along the Batang-Xichang line, and near the Mabian high gradient zones. In June 2012, the Yanyuan $M_{\mathrm{S}} 5.7$ earthquake occurred in a gravityvarying region of the high gradient zone. In September, however, the Yiliang $M_{\mathrm{S}} 5.7$ earthquake occurred near areas with high gravity anomalies. Fourth, the region on the southwestern side of the line (South Yushu-BatangXichang) demonstrates a positive gravity anomaly. The Yingjiang $2011 M_{\mathrm{S}} 5.8$ earthquake occurred within this gravity gradient belt.

Figure $3 \mathrm{~b}$ shows that changes in the gravitational field in eastern Tibet were negative in the west and positive in the east during the period 2010-2012. Changes in the gravitational field in eastern Tibet are negative in the west and positive in the east, indicating an enhanced activity of subterranean in the region. The gravity changes have the following features. First, in western Sichuan, more rapid gravity changes occurred in the 2011-2012 period than the 2010-2011 period (Fig. 3a). The Tibetan block appears to have moved toward the southeast but is restricted by the South China block, resulting in the redistribution of crustal material. Gravity variations change from positive in 2010-2011 to negative in 2011-2012 along the margin from Xining and Lanzhou to Qingchuan and Wenchuan, and then from Chengdu and Meishan, forming a high-gradient zone along the Longmenshan fault from Qingchuan to Lushan. The Lushan earthquake occurred at the turning point of the high gradient zone at the southern part of the Longmenshan fault. Second, intense gravity changes are also observed on the eastern edge of the Yunnan-Sichuan border, forming a high-gradient zone along the Longmenshan fault from Kangding, Xichang, to Qiaojia. On both sides of the gradient zone, the Yiliang $M_{\mathrm{S}} 5.7$ and Yanyuan $M_{\mathrm{S}} 5.7$ earthquakes occurred in 2012. Third, the southwestern Yunnan shows an obvious gradient belt but a reverse gravity change from the previous period. This is 

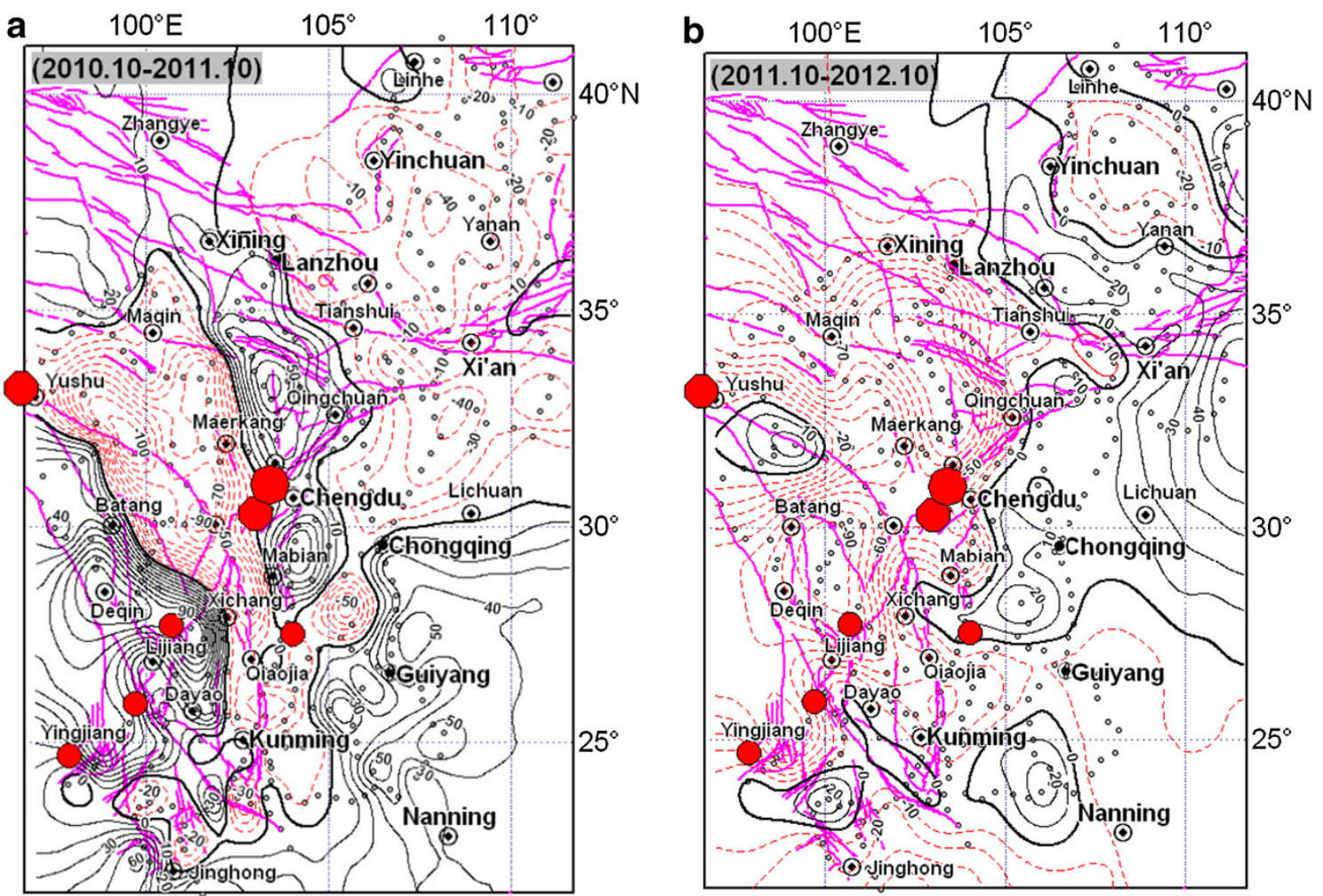

Fig. 3 Contours of the eastern margin of the Qinghai-Tibet Plateau (unit: $10^{-8} \mathrm{~m} \mathrm{~s}^{-2}$ )

due to the restoration of the Yingjiang $M_{\mathrm{S}} 5.8$ earthquake that occurred on 10 March 2011.

\subsection{2-Year gravity variations on the eastern margin of the Tibetan Plateau}

During the period 2010-2012 (Fig. 4), gravity changes have the following characteristics: (1) the general trend in gravity changes goes from negative in the west, to positive in the east. Large areas of western Sichuan show negative gravity anomalies, while a positive gravity anomaly with a smaller range appears in the Sichuan Basin. Along the Longmenshan fault, a positive-to-negative gravity gradient zone exists along Qingchuan-Lushan line. The Lushan M7.0 earthquake occurred in the southern part of the Longmenshan fault zone. (2) Around Xichang and Qianjia, high gravity changes exist on the eastern side of the Yunnan-Sichuan boarder, featuring four-quadrant variation: the gravity change of positive-negative-positivenegative in four directions. Two consecutive earthquakes (Yanyuan $M_{\mathrm{S}} 5.7$ and Yiliang $M_{\mathrm{S}} 5.7$ ) occurred in this region. (3) There have been no significant gravity changes observed in the western Yunnan. This is probably due to the fact that gravity changes occurred in opposite directions before and after the 10 March 2011 Yingjiang $M_{\mathrm{S}} 5.8$ earthquake. Figure 4 also shows that regional gravity changes have gradually been restored after the earthquake.

\section{Prediction of the Lushan earthquake based on gravity changes}

In November 2012, annual earthquake predictions were made by the CEA Second Monitoring Center for 2013 based on seismic data recorded by the Sichuan Seismic Monitoring Network and on mobile gravity observations from 2010 to 2012. This was made possible by observations from the comprehensive geophysical observation projects-eastern Tibet's gravitational field. The predictions were presented to the Survey Engineering Institute of the Sichuan Earthquake Administration. The prediction report indicated that an earthquake of magnitude 7 was likely to occur in the region near Baoxing, Tianquan, Kangding, Luding, and Shimian. This was based on the fact that the gravity differential movement had reached a magnitude of $100 \times 10^{-8} \mathrm{~m} \mathrm{~s}^{-2}$ and that a high gravity gradient zone exists along the southern part of the Longmenshan and Malcolm fault zones.

Before the Lushan $M_{\mathrm{S}} 7.0$ earthquake occurred, the CEA Second Monitoring Center observed obvious gravity anomalies in the region. These were based on temporal dynamic characteristics in the regional gravity field near the southern part of the Longmenshan fault. The most recent prediction released the following details: ${ }^{1}$

\footnotetext{
12013 Research report of earthquake tendency of Second Monitoring Center, China Earthquake Administration, 2012, 11, 120-134.
} 


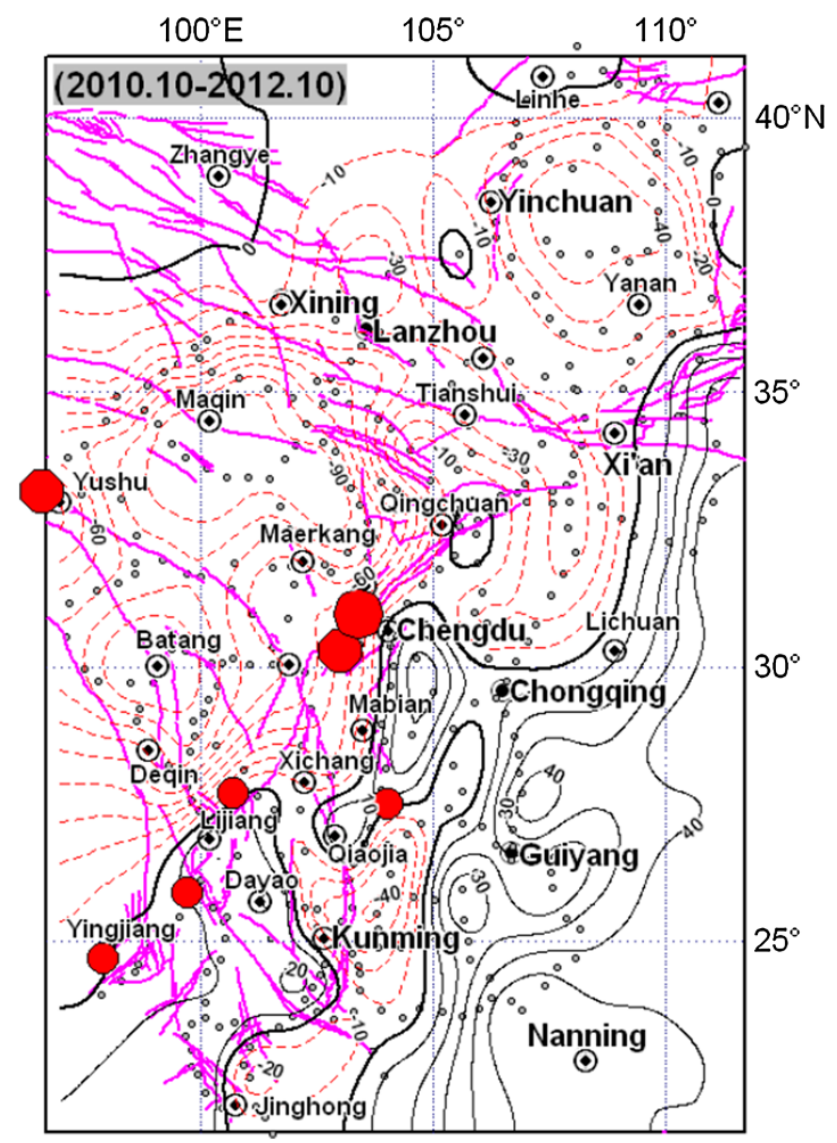

Fig. 4 Contours of the eastern margin of the Qinghai-Tibet Plateau (unit: $10^{-8} \mathrm{~m} \mathrm{~s}^{-2}$ )

Occurrence time: 2013.

Seismogenic location: western Sichuan including Baoxing, Vincent, Kangding, Luding, Shimian area (epicenter: $30.2^{\circ} \mathrm{N}, 102.2^{\circ} \mathrm{E}$, radius: $100 \mathrm{~km}$ range).

Magnitude: $M_{\mathrm{S}} 6.0$.

As can be seen above, the gravity-based prediction for the Lushan $M_{\mathrm{S}} 7.0$ earthquake $\left(30.3^{\circ} \mathrm{N}, 103.0^{\circ} \mathrm{E}, 20\right.$ April 2013), which occurred in the Lushan County, Sichuan, was very accurate. The predicted epicenter was less than $80 \mathrm{~km}$ away from the observed earthquake epicenter.

\section{Discussion and conclusions}

The stability of measuring points is the reliable premise of gravity measurement. In 2010, after China Earthquake Administration started the gravity change refined monitoring network, the most important work completed by six groups from three institutions is to inspect all points and to reconstruct the points that are not suitable and/or not stable. The inspection and reconstruction cost each group about 2 months to complete, ensuring stability of all points. The gravity data used in this study are observed from the points after the inspection and reconstruction.

The earthquake is a complex process of the Earth's interior, involving geology, geophysics, crustal deformation, and many other fields. The earthquake prediction discussed in this paper is only based on the analysis of gravity measurements in the eastern margin of the Tibetan Plateau. Our future study will include more precise precipitation and terrain corrections, in combination with geological structure and the physical mechanism.

Most earthquakes occur at active plate boundaries or on active faults. The Lushan $M_{\mathrm{S}} 7.0$ earthquake occurred in the southern part of the NE-trending Longmenshan fault zone. This paper studied changes in gravitational dynamics before the Lushan $M_{\mathrm{S}} 7.0$ earthquake occurred. Here, we list a few of our key findings:

(1) Before the 2013 Lushan $M_{\mathrm{S}} 7.0$ earthquake occurred, a new four-quadrant gravity distribution was identified near the epicenter of the 2008 Wenchuan $M_{\mathrm{S}} 8.0$ earthquake, indicating that the restoration of the Wenchuan earthquake may be a precursor to the Lushan earthquake. The restoration after the Wenchuan earthquake could have expedited the occurrence of the Lushan $M_{\mathrm{S}} 7.0$ earthquake.

(2) Gravity changes on the eastern edge of the Tibetan Plateau are precursors for the Lushan $M_{\mathrm{S}} 7.0$ earthquake. The earthquake occurred at the turning point of the region with large-scale regional gravity anomalies and associated high gravity gradient zones.

(3) The accurate prediction of the Wenchuan $M_{\mathrm{S}} 8.0$ and Lushan $M_{\mathrm{S}} 7.0$ earthquakes using gravity anomaly information shows that mobile gravity sensors are better indicators of changes in gravity prior to the occurrence of a strong earthquake. Regional gravity observations have unique advantages in determining the epicenters of future strong earthquakes.

Acknowledgments This work was supported by the National Natural Science Foundation of China (41274083) and Special Earthquake Research Project Grant by China Earthquake Administration (201208009). The authors wish to thank the Editor, the Associate Editor, and three anonymous referees for their thoughtful suggestions that helped to shape the article to its current form. Data discussed in this paper were collected and maintained by joint operations between China Earthquake Administration Wuhan Institute of Seismology, China Earthquake Administration First Crust Monitoring and Application Center, China Earthquake Administration Second Crust Monitoring and Application Center.

\section{References}

Chen YT, Gu HD, Lu ZX (1979) Variations of gravity before and after the Haicheng earthquake, 1975, and Tangshan earthquake, 1976. Phys Earth Planet Interior 18(4):330-338 
Hubbard J, Shaw JH (2009) Uplift of the Longmen Shan and Tibetan Plateau, and the 2008 Wenchuan $\left(M_{\mathrm{S}}=7.9\right)$ earthquake. Nature 458:194-197

Jiang ZS, Fang Y, Wu YQ, Wang M, Du F, Ping JJ (2009) The dynamic process of regional crustal movement and deformation before Wenchuan $M_{\mathrm{S}} 8.0$ earthquake. Chin J Geophys 52(2):505-518 (in Chinese with English abstract)

Li H, Shen CY, Sun SA, Wang XQ, Xiang AM, Liu SM (2011) Recent gravity changes in China Mainland. J Geodesy Geodyn 02(1):1-12

Lou H, Wang CY, Lv ZY, Yao ZX, Dai SG, You HC (2008) Deep tectonic condition of the $M_{\mathrm{S}} 8.0$ Wenchuan earthquake of Sichuan, China. Sci China D 38(10):1207-1220 (in Chinese with English abstract)

Teng JW, Bai DH, Yang H, Yan YF, Zhang HS, Zhang YQ, Ruan XM (2008) Deep processes and dynamic responses associated with the Wenchuan $M_{\mathrm{S}} 8.0$ earthquake of 2008. Chin J Geophys 51(5):1385-1402 (in Chinese with English abstract)

$\mathrm{Xu} \mathrm{HZ}$ (2003) Function of gravimetry in CMONOC. J Geodesy Geodyn 23(3):1-3 (in Chinese with English abstract)

Zhan FB, Zhu YQ, Ning JS, Zhou JC, Liang WF, Xu YM (2011) Gravity changes before large earthquakes in China: 1998-2005. Geo-spatial Inf Sci 14(1):01-09
Zhang PZ, Xu XW, Wen XZ, Ran YK (2008) Slip rate and recurrence intervals of the Longmenshan active fault zone, and tectonic implications for the mechanism of the May 12 Wenchuan earthquake 2008, Sichuan, China. Chin J Geophys 51(4):1066-1073 (in Chinese with English abstract)

Zhu YQ, Liang WF, Xu YM (2009a) Dynamic variation of gravity field before and after Wenchuan $M_{\mathrm{S}} 8.0$ earthquake. Acta Seismol Sin 32(6):633-640 (in Chinese with English abstract)

Zhu YQ, Xu YM, Lv GP (2009b) Relations between gravity variation of Longmenshan fault zone and Wenchuan $M_{\mathrm{S}} 8.0$ earthquake. Chin J Geophys 52(10):2538-2546 (in Chinese with English abstract)

Zhu YQ, Zhan FB, Zhou JC, Liang WF, Xu YM (2010) Gravity measurements and their variations before the 2008 Wenchuan earthquake. Bull Seismol Soc Am 100(5B):2815-2824

Zhu YQ, Liang WF, Zhan FB, Liu F, Xu YM, Guo SS, Liu L (2012a) Study on dynamic change of gravity field in China continent. Chin J Geophys 55(3):804-813 (in Chinese with English abstract)

Zhu YQ, Liu F, Cao JP, Zhao YF (2012b) Gravity changes before and after the $2010 M_{\mathrm{S}} 7.1$ Yushu earthquake. Geodesy Geodyn 03(4):1-7 